\title{
BMJ Open Prevalence, associated factors and heritabilities of metabolic syndrome and its individual components in African Americans: the Jackson Heart Study
}

\author{
Rumana J Khan, ${ }^{1}$ Samson Y Gebreab, ${ }^{1}$ Mario Sims, ${ }^{2}$ Pia Riestra, ${ }^{1}$ Ruihua Xu, ${ }^{1}$ \\ Sharon K Davis ${ }^{1}$
}

To cite: Khan RJ,

Gebreab SY, Sims M, et al. Prevalence, associated factors and heritabilities of metabolic syndrome and its individual components in African Americans: the Jackson Heart Study. BMJ Open 2015;5:e008675. doi:10.1136/bmjopen-2015008675

- Prepublication history for this paper is available online. To view these files please visit the journal online (http://dx.doi.org/10.1136/ bmjopen-2015-008675).

Received 4 May 2015 Revised 12 August 2015 Accepted 2 September 2015

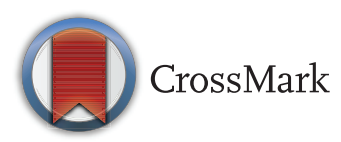

${ }^{1}$ Cardiovascular Section, Metabolic, Cardiovascular and Inflammatory Disease Genomics Branch, National Human Genome Research Institute, National Institutes of Health, Bethesda, Maryland, USA

${ }^{2}$ Division of Hypertension, Department of Internal Medicine, University of Mississippi Medical Center, Jackson, Mississippi, USA

Correspondence to Rumana J Khan; rumana.khan@nih.gov

\section{ABSTRACT}

Objective: Both environmental and genetic factors play important roles in the development of metabolic syndrome (MetS). Studies about its associated factors and genetic contribution in African Americans (AA) are sparse. Our aim was to report the prevalence, associated factors and heritability estimates of MetS and its components in AA men and women.

Participants and setting: Data of this crosssectional study come from a large community-based Jackson Heart Study (JHS). We analysed a total of 5227 participants, of whom 1636 from 281 families were part of a family study subset of JHS.

Methods: Participants were classified as having MetS according to the Adult Treatment Panel III criteria. Multiple logistic regression analysis was performed to isolate independently associated factors of MetS $(n=5227)$. Heritability was estimated from the family study subset using variance component methods ( $n=1636)$.

Results: About $27 \%$ of men and $40 \%$ of women had MetS. For men, associated factors with having MetS were older age, lower physical activity, higher body mass index, and higher homocysteine and adiponectin levels ( $p<0.05$ for all). For women, in addition to all these, lower education, current smoking and higher stress were also significant ( $p<0.05$ for all). After adjusting for covariates, the heritability of MetS was $32 \%(p<0.001)$. Heritability ranged from 14 to $45 \%$ among its individual components. Relatively higher heritability was estimated for waist circumference (45\%), high density lipoprotein-cholesterol (43\%) and triglycerides (42\%). Heritability of systolic blood pressure (BP), diastolic BP and fasting blood glucose was 16\%, 15\% and $14 \%$, respectively.

Conclusions: Stress and low education were associated with having MetS in AA women, but not in men. Higher heritability estimates for lipids and waist circumference support the hypothesis of lipid metabolism playing a central role in the development of MetS and encourage additional efforts to identify the underlying susceptibility genes for this syndrome in AA.

\section{Strengths and limitations of this study}

- The African American community disproportionately suffers from metabolic syndrome, but relatively little is known about the genetic contribution and the environmental influence of this syndrome among African Americans.

- Using the data from a large community-based Jackson Heart study, this study showed a high prevalence of metabolic syndrome, and reported the associated factors and heritability estimates of metabolic syndrome and its components in African Americans.

- We are not aware of any published data that explored these issues among African Americans from such a big setting. The large sample size also provided a more reliable statistical ground to detect heritability estimates than nuclear families, twin pair data or sib-pair data.

- Potential limitations of this study included the cross-sectional observational design, which could only confirm the associations of the factors with metabolic syndrome, but not the causality, and the absence of information on shared environmental factors like childhood environment and neighbourhood factors, which might slightly overestimate the heritability results.

- This study encourages additional efforts to identify the underlying susceptibility genes for metabolic syndrome among African Americans.

\section{BACKGROUND}

Metabolic syndrome (MetS) is a clustering of different interrelated cardiometabolic risk factors including obesity, elevated blood pressure (BP), dyslipidemia and impaired fasting plasma glucose (IFG). These risk factors often occur together and increase cardiovascular disease (CVD) deaths almost by threefold to fourfold. ${ }^{1}{ }^{2}$ Since MetS is the 
combined effect of more than one risk factor, its aetiology is complex. Factors like lifestyle, gender, ethnicity, socioeconomic status, psychosocial factors and some inflammatory markers play key roles in the pathogenesis of MetS. ${ }^{1-3}$ Findings also suggest that MetS clusters in families $^{4-8}$ and has reasonable heritability, which is defined as the proportion of phenotypic variance in a trait that is attributable to the additive effects of genes. ${ }^{9-17}$ Thus, the interplay of environmental and genetic factors makes MetS a multifactorial disorder.

Though the pathogenesis, diagnosis and the treatment of MetS remain complex because of its multifactorial nature, the construct MetS is an important risk-assessment method for early detection and early intervention of CVD. In spite of the steady decline in CVD mortality during recent decades, CVD is still the leading cause of death in all Americans, and is highly prevalent in persons of African ancestry. ${ }^{18}$ It is important to note that the majority of studies that explored the associated factors and quantified the heritability of MetS almost exclusively involved Caucasians. ${ }^{10-14} 19$ Relatively little is known about these issues among the adult African American (AA) population. ${ }^{15-17}$ Using the Jackson Heart Study (JHS) data, the objective of this cross-sectional study was to report the prevalence, risk factors and heritability estimates of MetS and its components in AA men and women.

\section{METHODS}

\section{Data source}

The data for this analysis come from a large communitybased JHS, which comprises 5301 adult AA enrolled between September 2000 and March 2004 and residing in Jackson, Mississippi metropolitan area. ${ }^{20}$ About $24 \%$ of the 5301 adult AA participated in the JHS family study component. $^{21}$ The family study component of JHS contained first degree (parent-offspring and siblings), second degree (grandparent-grandchild, avuncular, halfsiblings) and third degree or more distant (great grandparent-grandchild, grand avuncular, half avuncular, first cousins, half first cousins, second cousins) family members. The JHS was approved by the University of Mississippi Medical Center Institutional Review Board, and the participants gave written informed consent. Details of the study design and data collection methods are described elsewhere. ${ }^{21} 22$ The current study data were obtained from the baseline clinic visit during 2000-2004. After excluding 74 participants who did not have information on their MetS status, the current analysis had a total of 5227 participants, of whom 1636 from 281 families contributed to the heritability analyses.

\section{Measures}

We collected information on participant's waist circumference (WC), systolic BP (SBP) and diastolic BP (DBP), fasting plasma glucose (FPG), fasting triglyceride and plasma high-density lipoprotein cholesterol (HDL-C).
Two measures of the waist at the level of the umbilicus and in the upright position were averaged to calculate WC. Sitting BP was measured twice at 5 min intervals with a standardised Hawksley random-zero sphygmomanometer, and the average of two measurements was used. Fasting blood samples were collected according to standardised protocols, and the assessments of FPG and lipids were processed at the Central Laboratory, University of Minnesota. ${ }^{23}$ Respondents were asked about their medication usage for hypertension, diabetes mellitus and high lipid levels. Individuals were classified as having MetS if they had at least three of the following five components: (1) large WC or abdominal obesity (>102 cm for men and $>88 \mathrm{~cm}$ for women); (2) hypertriglyceridaemia (fasting plasma triglyceride concentration $\geq 150 \mathrm{mg} / \mathrm{dL}$ or on drug treatment); (3) low HDL-C levels $(<40 \mathrm{mg} / \mathrm{dL}$ for men and $<50 \mathrm{mg} / \mathrm{dL}$ in women or on drug treatment); (4) elevated $\mathrm{BP}(\geq 130 \mathrm{~mm} \mathrm{Hg}$ SBP or $\geq 85 \mathrm{~mm} \mathrm{Hg}$ DBP or on drug treatment); or (5) IFG $\left(\geq 110 \mathrm{mg} / \mathrm{dL}\right.$ or on drug treatment).$^{24} 25$

Data about socio-demographic (age, sex and education), psychosocial (stress) and lifestyle (physical activity, smoking status and alcohol consumption) variables were also collected. Age was classified as: 20-39, 40-59, 60-79 and 80 years and above. Education status was selfreported and was divided into three categories (less than high school, high school/some college and college/associate degree or higher, where less than high school was the referent). Stress level was obtained from The Global Perceived Stress Scale, an 8-item questionnaire that measures the severity of chronic stress experienced over a prior period of 12 months. ${ }^{26}$ The physical activity index composite score was calculated as the sum of four different domains of physical activity: active living, work, home and garden, and sport and exercise indices. ${ }^{27}$ Smoking status was classified as never (referent), current and former. Alcohol consumption status was defined as 'yes' if the participants currently consumed alcoholic beverages and 'no' (referent) if they had stopped drinking for more than a year, or if they never consumed alcohol. Information on clinical factors like body mass index BMI (weight in $\mathrm{kg}$ divided by height in meter square), $\mathrm{C}$ reactive protein or CRP $(\mathrm{mg} / \mathrm{dL})$, serum adiponectin $(\mathrm{mg} / \mathrm{dL})$ and serum homocysteine $(\mu \mathrm{mol} / \mathrm{L})$ was also obtained. ${ }^{23}$

\section{Analysis}

Data from the full cohort $(n=5227)$ were used to explore the risk factors of MetS. Sociodemographic, psychosocial, lifestyle and clinical characteristics of participants were compared by gender and MetS status using the $\chi^{2}$ or independent $\mathrm{t}$ test. The primary outcome measure for this analysis was the presence of MetS, evaluated as a dichotomous variable. Logistic regression analysis was used to examine the association between each independent variable (age, education level, stress level, physical activity score, smoking status, alcohol consumption status, BMI, CRP, fasting total cholesterol, serum 
concentration of adiponectin and serum homocysteine) and the outcome of MetS. A multiple logistic regression model was fitted including all variables to isolate the statistically significant predictors of MetS. The regression analysis was conducted using SAS software, V.9.3. ${ }^{28}$

\section{Heritability analysis}

After checking the pedigree data for inconsistencies, a total of 1636 individuals from 281 families were analysed to calculate the heritability estimates by variance component methods using the SOLAR (Sequential Oligogenic Linkage Analysis Routines) software package to quantify the proportion of the variance in MetS and in its individual components that was attributable to the additive effects of genes. ${ }^{29}$ We estimated the heritabilities of individual MetS components (treated as continuous variable) including WC, SBP, DBP, FPG, fasting triglyceride and plasma HDL-C with adjustment for age, education level, physical activity index composite score, smoking status, alcohol consumption status and respective medication usage. Log transformed values of FPG and triglycerides were used due to deviation from the normal distribution. Heritabilities were calculated using a standard quantitative genetic variance-components model implemented in SOLAR. ${ }^{29}$ This approach uses the maximum-likelihood estimation to a mixed-effects model that incorporates fixed covariate effects, additive genetic effects and residual error. The heritability of MetS (discrete variable) was analysed by a threshold model in SOLAR. The method assumed that an individual belonged to a specific affected status if an underlying genetically determined risk exceeded a certain threshold. ${ }^{30}$

For all the analyses, a significance level set at $\mathrm{p}<0.05$ was used.

\section{RESULTS}

Table 1 presents the characteristics of JHS participants. Of the 5227 individuals, $1909 \quad(36.52 \%$, mean age 53.93 years and standard deviation or $\mathrm{SD}=12.93$ ) were men and $3318(63.48 \%$, mean age $55.30 \pm 12.76)$ were women. Education levels were similar for men and

Table 1 Characteristics of Participants of the Jackson Heart Study by Gender ( $N=5227)$

\begin{tabular}{|c|c|c|c|c|}
\hline & $\begin{array}{l}\text { Total }^{*} \\
\mathrm{n}=5227\end{array}$ & $\begin{array}{l}\text { Men* } \\
n=1909\end{array}$ & $\begin{array}{l}\text { Women* } \\
\mathrm{n}=3318\end{array}$ & p Valuet \\
\hline Age in years & $54.87(12.84)$ & $53.93(12.93)$ & $55.30(12.76)$ & 0.0002 \\
\hline \multicolumn{5}{|l|}{ Education level } \\
\hline Less than high school & 18.4. & 18.73 & 17.88 & \\
\hline High school or some college & 42.2 & 42.82 & 41.83 & \\
\hline College/associate degree or higher & 39.4 & 38.45 & 40.29 & 0.4094 \\
\hline \multicolumn{5}{|l|}{ Smoking status } \\
\hline Never & 67.9 & 56.68 & 74.59 & \\
\hline Former & 18.9 & 25.33 & 15.30 & \\
\hline Current & 13.2 & 17.99 & 10.11 & $<0.0001$ \\
\hline \multicolumn{5}{|l|}{ Alcohol drinking status } \\
\hline Yes & 47.2 & 58.92 & 38.41 & \\
\hline No & & 41.08 & 61.59 & $<0.0001$ \\
\hline Total physical activity score $\ddagger$ & $8.31(2.61)$ & $8.64(2.63)$ & $8.16(2.58)$ & $<0.0001$ \\
\hline Global stress total score§ & $5.14(4.21)$ & $4.50(4.20)$ & $5.52(4.45)$ & $<0.0001$ \\
\hline Body mass index (weight in kg/height in squared meter) & $31.75(7.24)$ & $29.83 \pm 6.14$ & $32.86(7.59)$ & $<0.0001$ \\
\hline High-sensitivity $\mathrm{C}$ reactive protein in $\mathrm{mg} / \mathrm{dL}$ & $0.51(0.87)$ & $0.35(0.96)$ & $0.60(0.85)$ & $<0.0001$ \\
\hline Homocysteine in $\mu \mathrm{mol} / \mathrm{L}$ & $9.44(4.68)$ & $10.17(3.56)$ & $9.00(5.20)$ & $<0.0001$ \\
\hline Adiponectin level in $\mu \mathrm{g} / \mathrm{mL}$ & $5.41(4.16)$ & $4.15(3.41)$ & $6.15(4.57)$ & $<0.0001$ \\
\hline Abdominal obesity & 62.9 & 41.03 & 75.70 & $<0.0001$ \\
\hline Hypertriglyceridaemia** & 16.5 & 18.39 & 13.23 & $<0.0001$ \\
\hline Low HDL-C†† & 37.2 & 33.01 & 39.55 & $<0.0001$ \\
\hline Elevated blood pressure $\ddagger$ & 70.3 & 69.62 & 70.58 & 0.4616 \\
\hline impaired fasting glucose§§ & 22.4 & 19.64 & 22.45 & 0.0171 \\
\hline Metabolic syndromeףी & 34.4 & 27.34 & 38.94 & $<0.0001$ \\
\hline \multicolumn{5}{|c|}{ 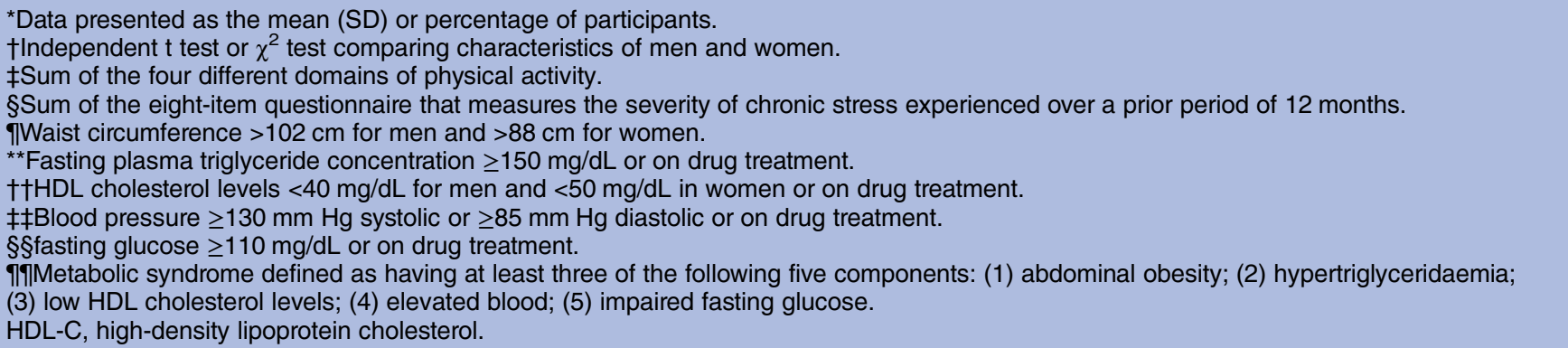 } \\
\hline
\end{tabular}


women. About $40 \%$ of men and women had college level education or beyond. A clear gender difference, however, was found for alcohol use and smoking, with women being far less likely than men to consume alcohol and smoke cigarettes $(p<0.001)$. Women reported greater levels of stress, but lower levels of physical activity than men $(p<0.001)$. Women also had higher BMI, CRP and adiponectin levels but lower homocysteine levels than men $(\mathrm{p}<0.001$ for all). Table 1 also shows the prevalence of MetS and its individual components among the JHS participants. About $27.34 \%$ of the men and $38.94 \%$ of the women had MetS $(\mathrm{p}<0.001)$. In terms of individual components, women had higher abdominal obesity $(75.70 \%$ vs $41.03 \%$, $\mathrm{p}<0.001)$ and IFG $(22.45 \%$ vs $19.64 \%, \mathrm{p}<0.001)$, but lower hypertriglyceridaemia $(13.23 \%$ vs $18.39 \%$, $\mathrm{p}<0.001)$ than men.

Table 2 shows the descriptive characteristics of participants by MetS status. Those who had MetS were older, less educated, less likely to smoke, less likely to consume alcohol and less physically active $(p<0.001$ for all $)$. They also had higher BMI, CRP and homocysteine levels but a lower adiponectin concentration $(p<0.001$ for all). The unadjusted and the adjusted relationships of MetS with these features are displayed in table 3. After adjustment, older age remained significant for both men and women. Notably, the trend of having MetS with increasing age was clearer for women than for men. Education was only significant for women but not for men. Women who went to high school had 24\% (adjusted odds ratio or AOR: 0.76 ; $95 \%$ confidence interval or CI: 0.59 to 0.97) decreased odds of having MetS compared to those who had the lowest education level. Like education, higher stress level was also a significant factor for women only (AOR: 1.02; 95\% CI: 1.01 to 1.04 ). Physical activity decreased the odds of having MetS for both sexes, but alcohol consumption was associated with $26 \%$ decreased odds (AOR: 0.74; 95\% CI: 0.61 to 0.90 ) of MetS for women only. Relationship between smoking and MetS was different for men and women. While current smoking only predicted women's MetS (AOR: 1.43; 95\% CI: 1.07 to 1.91), former smoking had a significant association with men's MetS (AOR: 1.54; 95\% CI: 1.14 to 2.08). Biomedical risk factors such as increased BMI (AOR: 1.18; 95\% CI: 1.15 to 1.21 for men and AOR: 1.08 ; $95 \%$ CI: 1.07 to 1.10 for women), increased serum homocysteine (AOR: 1.05; 95\% CI: 1.02 to 1.09 for men and AOR: 1.06 ; $95 \%$ CI: 1.03 to 1.09 for women) and decreased serum adiponectin (AOR: 0.90; 95\% CI: 0.85 to 0.95 for men and AOR: $0.90 ; 95 \%$ CI: 0.87 to 0.92 for women) were associated with increased odds of having MetS for both sexes.

Table 4 illustrates the heritability estimates along with the proportion of variation explained by covariates $\left(\sigma_{\mathrm{e}}^{2}\right)$ of MetS and its individual component in the family study subset $(\mathrm{n}=1636)$. All components of MetS were significantly correlated with each other except for the pairs of BP and HDL-C and BP and fasting glucose (results not shown in table). After accounting for the covariates (except medication), the heritability of MetS

Table 2 Characteristics of the Jackson Heart Study Participants by metabolic syndrome status $(\mathrm{N}=5227)$

\begin{tabular}{|c|c|c|c|}
\hline & $\begin{array}{l}\text { Metabolic Syndrome* } \\
(\mathrm{n}=1814)\end{array}$ & $\begin{array}{l}\text { No Metabolic } \\
\text { Syndrome }(n=3413)\end{array}$ & p Value \\
\hline Age in years & $58.04(11.43)$ & $53.07(13.21)$ & $<0.0001$ \\
\hline \multicolumn{4}{|l|}{ Gender of participant } \\
\hline Men & 28.78 & 40.46 & \\
\hline Women & 71.22 & 59.36 & $<0.0001$ \\
\hline \multicolumn{4}{|l|}{ Education level } \\
\hline Less than high school & 23.32 & 15.46 & \\
\hline High school or some college & 41.94 & 42.33 & \\
\hline College/associate degree or higher & 34.74 & 42.21 & $<0.0001$ \\
\hline \multicolumn{4}{|l|}{ Smoking status } \\
\hline Never & 66.17 & 69.05 & \\
\hline Former & 21.59 & 17.56 & \\
\hline Current & 12.24 & 13.39 & 0.0017 \\
\hline \multicolumn{4}{|l|}{ Alcohol drinking status } \\
\hline Yes & 37.01 & 50.63 & \\
\hline No & 62.99 & 49.37 & $<0.0001$ \\
\hline Total physical activity scoreł & $7.74(2.56)$ & $8.65(2.57)$ & $<0.0001$ \\
\hline Global stress total score§ & $5.11(4.42)$ & $5.17(4.37)$ & 0.6251 \\
\hline Body mass index (weight in $\mathrm{kg} /$ height in squared meter) & $34.87(6.92)$ & $30.10(6.86)$ & $<0.0001$ \\
\hline High-sensitivity $\mathrm{C}$ reactive protein in $\mathrm{mg} / \mathrm{dL}$ & $0.65(1.13)$ & $0.44(0.74)$ & $<0.0001$ \\
\hline Homocysteine: The concentration of homocysteine in $\mu \mathrm{mol} / \mathrm{L}$ & $9.94(6.37)$ & $9.15(3.44)$ & $<0.0001$ \\
\hline Serum concentration of adiponectin in $\mu \mathrm{g} / \mathrm{mL}$ & $4.72(4.02)$ & $5.79(4.38)$ & $<0.0001$ \\
\hline
\end{tabular}

${ }^{*}$ Data presented as the mean (SD) or percentage of participants.

†Independent t-test or $\chi^{2}$ test.

¥Sum of the four different domains of physical activity.

$\S S u m$ of the eight-item questionnaire that measures the severity of chronic stress experienced over a prior period of 12 months. 
Table 3 Association between selected factors and prevalence of metabolic syndrome among the Jackson Heart Study Participants $(n=5227)$

\begin{tabular}{|c|c|c|c|c|}
\hline & \multicolumn{4}{|c|}{$\begin{array}{l}\text { Metabolic syndrome } \\
\text { OR }(95 \% \mathrm{Cl})\end{array}$} \\
\hline & \multicolumn{2}{|l|}{ Men $(n=1909)$} & \multicolumn{2}{|l|}{ Women $(n=3318)$} \\
\hline & Unadjusted $^{\star}$ & Adjusted $^{*}$ & Unadjusted* $^{\star}$ & Adjusted* $^{*}$ \\
\hline \multicolumn{5}{|l|}{ Age } \\
\hline 20-39 & Reference level & & Reference level & \\
\hline $40-59$ & $1.34(0.96$ to 1.86$)$ & 1.55 (1.02 to 2.35$)$ & 2.44 (1.84 to 3.23$)$ & 2.79 (2.00 to 3.87$)$ \\
\hline $60-79$ & 1.69 (1.20 to 2.38$)$ & 2.17 (1.34 to 3.51$)$ & 4.69 (3.54 to 6.22$)$ & 5.50 (3.81 to 7.93$)$ \\
\hline 80 and above & $0.88(0.28$ to 2.71$)$ & $2.18(0.60$ to 8.00$)$ & 3.43 (1.89 to 6.24$)$ & $5.06(2.34$ to 10.96$)$ \\
\hline \multicolumn{5}{|l|}{ Education } \\
\hline Less than High school & Reference level & & Reference level & \\
\hline High school or some college & $0.95(0.72$ to 1.25$)$ & $1.20(0.83$ to 1.74$)$ & $0.53(0.44$ to 0.65$)$ & $0.76(0.59$ to 0.97$)$ \\
\hline College degree or higher & $0.79(0.60$ to 1.05$)$ & $1.05(0.72$ to 1.55$)$ & $0.44(0.36$ to 0.53$)$ & $0.82(0.63$ to 1.07$)$ \\
\hline \multicolumn{5}{|l|}{ Smoking status } \\
\hline Never & Reference level & & Reference level & \\
\hline Former & $1.47(1.16$ to 1.85$)$ & $1.54(1.14$ to 2.08$)$ & $1.39(1.15$ to 1.69$)$ & $1.20(0.95$ to 1.52$)$ \\
\hline Current & $0.92(0.69$ to 1.22$)$ & $1.29(0.89$ to 1.86$)$ & $1.20(0.95$ to 1.51$)$ & $1.43(1.07$ to 1.91$)$ \\
\hline \multicolumn{5}{|l|}{ Alcohol drinking } \\
\hline No & Reference level & & Reference level & \\
\hline Yes & $0.72(0.59$ to 0.88$)$ & $0.85(0.66$ to 1.11$)$ & $0.57(0.49$ to 0.66$)$ & 0.74 (0.61 to 0.90$)$ \\
\hline Physical activity† & 0.90 (0.86 to 0.94$)$ & 0.93 (0.88 to 0.98$)$ & 0.86 (0.84 to 0.89$)$ & 0.94 (0.91 to 0.98$)$ \\
\hline Global stress $\ddagger$ & 1.01 (0.98 to 1.03$)$ & $1.02(0.99$ to 1.06$)$ & 0.98 (0.97 to 1.00$)$ & $1.02(1.01$ to 1.04$)$ \\
\hline Body mass index & $1.18(1.15$ to 1.20$)$ & $1.18(1.15$ to 1.21$)$ & 1.08 (1.07 to 1.09$)$ & 1.08 (1.07 to 1.10$)$ \\
\hline$C$ reactive protein in $\mathrm{mg} / \mathrm{dL}$ & $1.36(1.15$ to 1.60$)$ & $1.10(0.96$ to 1.26$)$ & $1.29(1.18$ to 1.41$)$ & 0.99 (0.89 to 1.09$)$ \\
\hline Homocysteine in $\mu \mathrm{mol} / \mathrm{L}$ & $1.04(1.01$ to 1.07$)$ & 1.05 (1.02 to 1.09$)$ & $1.07(1.05$ to 1.10$)$ & $1.06(1.03$ to 1.09$)$ \\
\hline Adiponectin in $\mu \mathrm{g} / \mathrm{mL}$ & $0.89(0.85$ to 0.92$)$ & $0.90(0.85$ to 0.95$)$ & $0.91(0.90$ to 0.93$)$ & 0.90 (0.87 to 0.92$)$ \\
\hline \multicolumn{5}{|c|}{ 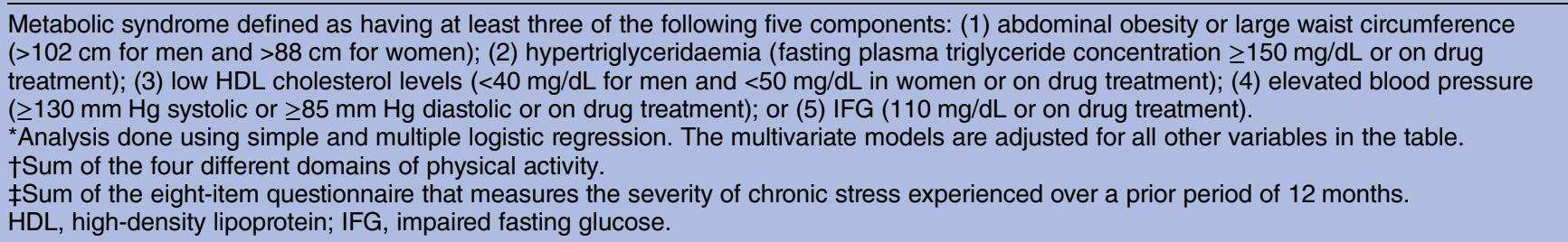 } \\
\hline
\end{tabular}

was about $32 \%\left(\mathrm{p}<0.0001, \sigma_{\mathrm{e}}^{2}: 10 \%\right)$. The adjusted heritability of individual MetS components ranged from the lowest of $14 \%\left(\mathrm{p}<0.01, \sigma_{\mathrm{e}}^{2}: 33 \%\right)$ for FPG to the highest of $45 \%\left(\mathrm{p}<0.0001, \sigma_{\mathrm{e}}^{2}: 8 \%\right)$ for WC after adjusting for all the covariates. The adjusted estimates of DBP $\left(15 \%, \mathrm{p}<0.01, \sigma_{\mathrm{e}}^{2}: 9 \%\right)$ and SBP $(16 \%, \mathrm{p}<0.001$,

Table 4 Heritability estimates of metabolic syndrome and its individual components of the Jackson Heart Study Participants $(n=1636)$

\begin{tabular}{|c|c|c|c|c|}
\hline & Heritability estimate & SE & p Value & $\begin{array}{l}\text { Proportion of variation } \\
\text { explained by covariates }\end{array}$ \\
\hline Metabolic syndrome* & 0.32 & 0.08 & $<0.0001$ & $0.10 \dagger$ \\
\hline Fasting plasma glucose $\ddagger \S$ & 0.14 & 0.06 & $<0.01$ & 0.339 \\
\hline Waist circumference $\ddagger$ & 0.45 & 0.06 & $<0.0001$ & $0.08 \dagger$ \\
\hline High-density lipoprotein cholesterol & 0.43 & 0.07 & $<0.0001$ & 0.119 \\
\hline Fasting triglyceride $\ddagger \S$ & 0.42 & 0.05 & $<0.0001$ & 0.109 \\
\hline Systolic blood pressureł & 0.16 & 0.07 & $<0.001$ & 0.229 \\
\hline Diastolic blood pressure $\neq$ & 0.15 & 0.05 & $<0.01$ & $0.09 \rrbracket$ \\
\hline \multicolumn{5}{|c|}{$\begin{array}{l}\text { *Treated as a discrete trait, and defined as having at least three of the following five components: (1) abdominal obesity or large waist } \\
\text { circumference ( }>102 \mathrm{~cm} \text { for men and }>88 \mathrm{~cm} \text { for women); (2) hypertriglyceridaemia (fasting plasma triglyceride concentration } \geq 150 \mathrm{mg} / \mathrm{dL} \text { or } \\
\text { on drug treatment); (3) low } \mathrm{HDL} \text { cholesterol levels }(<40 \mathrm{mg} / \mathrm{dL} \text { for men and }<50 \mathrm{mg} / \mathrm{dL} \text { in women or on drug treatment); (4) elevated blood } \\
\text { pressure ( } \geq 130 \mathrm{~mm} \mathrm{Hg} \text { systolic or } \geq 85 \mathrm{~mm} \mathrm{Hg} \text { diastolic or on drug treatment); or }(5) \mathrm{IFG}(110 \mathrm{mg} / \mathrm{dL} \text { or on drug treatment). } \\
\text { tCovariates are age, sex, education, smoking status, alcohol intake, physical activity. } \\
\text { †Treated as a continuous trait. } \\
\text { §Log transformed. } \\
\text { ๆCovariates are age, sex, education, smoking status, alcohol intake, physical activity and respective medication. } \\
\text { HDL, high-density lipoprotein; IFG, impaired fasting glucose. }\end{array}$} \\
\hline
\end{tabular}


$\left.\sigma_{\mathrm{e}}^{2}: 22 \%\right)$ were at the lower end and similar to the estimate of FPG. Conversely, heritability of triglyceride $\left(42 \%, \mathrm{p}<0.001, \sigma_{\mathrm{e}}^{2}: 10 \%\right)$ and HDL-C $(43 \%, \mathrm{p}<0.001$, $\sigma_{\mathrm{e}}^{2}: 11 \%$ ) was relatively high and similar to the heritability of WC.

\section{DISCUSSION}

We provide here the epidemiological and heritability data about MetS and its related traits according to ATP III criteria among AA. Overall, in our study sample, the prevalence of MetS was higher among women than among men. Factors independently associated with having MetS for men were older age, lower physical activity level, higher BMI, higher level of homocysteine and lower level of adiponectin. For women, in addition to older age, lower physical activity level, higher BMI, higher level of homocysteine and lower level of adiponectin, low education, higher stress, current smoking and alcohol consumption were also significant. The heritability of MetS was 32\% and among its individual components, heritability ranged from $14 \%$ for FPG to $45 \%$ for WC.

The prevalence of MetS that we found $(38.94 \%$ of women and $27.34 \%$ of men) was almost identical to a recent estimate from a National Survey, which reported that $38.2 \%$ of AA women and $25.5 \%$ of AA men had MetS. ${ }^{1}$ A higher prevalence of MetS in women than in men has been reported in several other Asian and Eastern European countries, as well as among Hispanics and Native Americans. ${ }^{131-33}$ However, it is opposite for US Caucasians with a higher prevalence in men. ${ }^{1}$ This, together with our finding, suggests the possibility of an increased risk of MetS for women belonging to an economically disadvantaged or minority population group. The unfavourable condition of women was also evident from our multivariate analysis, where we found lower education and stress to be significantly related to MetS for women, but not for men. While social class and education are typically inversely related to different cardiometabolic risk factors regardless of gender in the industrialised society, ${ }^{34-36}$ in our study this was true only for women, indicating an adverse social environment of our women participants.

Literature has indicated active smoking to be associated with development of MetS. ${ }^{37} 38$ We, however, found active smoking to be associated with women's MetS only. The lack of association between current smoking and MetS among men in our study can be partly attributed to the much discussed inverse association between active smoking and obesity, as the smoking prevalence was higher and abdominal obesity was relatively lower in the men than women in our analysis. ${ }^{39}$ Further, researchers have also found smoking cessation to be frequently followed by weight gain, ${ }^{40}$ which explains our observed association between past smoking and men's MetS.
Although lifestyle, physiological and sociodemographic factors play key roles in the pathogenesis of MetS, there is also strong evidence that the syndrome is inherited. $^{41-44}$ We evaluated the contributions of genetic factors to the phenotypic variability of MetS and its traits by heritability estimation. According to various studies from different ethnic groups, heritability of MetS ranges from approximately $19-38 \% .{ }^{10-13} \mathrm{~A}$ Dutch study estimated a heritability of $19.2 \%$ of MetS in an isolated group of population. ${ }^{11}$ A heritability of $24 \%$ in a Caribbean-Hispanic population has been reported by Lin et $a l^{12}$ The heritability for the Caucasian population was about $27 \%$ according to a large population-based study. ${ }^{10}$ Bayoumi $e t ~ a l^{13}$ reported a heritability of $38 \%$ of MetS in healthy Omani Arab families. Besides the genetic effect itself, which could be different among the different studied populations, the discrepancy in heritability might be attributable to other factors such as different sample sizes and a different structure of pedigrees or covariates included in the analysis. Compared to different ethnic groups, relatively little information is available on the heritability of MetS in AA population. The heritability of MetS in our study was $32 \%$ after taking into account the contributions of covariates, like age, sex, alcohol consumption, smoking and physical activity level, suggesting that more than one-third of the variance in MetS was attributable to the additive effects of genes in the JHS participants. This estimate is at the higher end of the heritability range reported so far, which suggests significant genetic influences on clustering of risk factors among AA.

Reported heritability from different studies for the individual traits ranges from $10 \%$ for plasma glucose to $60 \%$ for HDL-C. ${ }^{10-14} 19$ Our estimates correspond well to these findings. In the present study, more than $40 \%$ of the variance in HDL-C, triglyceride and WC was attributable to genetic effects. Conversely, a moderate but significant heritability was observed for BP and FPG. In different studies as well, HDL-C, obesity and lipid profiles showed the strongest heritability, and BP and FPG had the lowest heritability. ${ }^{10-14}$ While genetic influence remains dominant for lipid levels and WC, it seems that for FPG and BP the environmental contribution plays a more prominent role, which was apparent by the remarkable covariate effect that was observed for FPG and BP (33\% and 22\%, respectively) both in our findings and in those of some other studies. ${ }^{10}{ }^{12}$ This hypothesis is further supported by some genetic association studies, where investigators have tried to find a unifying pathogenic mechanism for the different MetS components and identify genetic variants contributing to MetS. No such work among AA was found, but a meta-analysis of 4000 Asian and Caucasian participants reviewing 25 genes reported an association between MetS and single nucleotide polymorphisms in the FTO, TCFL72, IL6, APOA5, APOC3 and CETP genes. $^{45}$ Another Swedish study found that genetic variants in the PPARG and ADRB1 genes conferred an increased risk of 
future MetS. ${ }^{46}$ All of these genes are mostly involved in lipid metabolism. ${ }^{45} 46$ These evidence indicate that lipid metabolism plays the central role in MetS development; and possibly, genetic impact of FPG and BP is relatively minor in MetS clusters. Our finding also indirectly supports this view as we found triglyceride, HDL-C and WC to be strongly correlated with one another and a relatively weaker correlation for BP and FPG with other traits. More importantly, we also found higher and similar heritability estimates for triglyceride, HDL-C and WC and relatively lower heritability estimates for BP and FPG, suggesting a possible similarity in the genetic mechanism of developing MetS for the AA population with other ethnic groups.

Our findings reconfirm that MetS is a complex disease and lifestyle, socioeconomic status and genetic background play important roles in the development of MetS. It was obvious from our study that the social and economic context has a disparate impact on women's cardiovascular health and that subsequent policies and health educational programmes should be particularly directed towards women for future CVD risk reduction. As the causes of MetS are reversible and the individual components are modifiable, lifestyle change such as increasing physical activity may reduce the prevalence of MetS in AA people. We found a significant and independent inverse association between MetS and adiponectin, and a positive association between MetS and homocysteine. In line with our findings, a number of recent studies also have reported similar results. ${ }^{47-51}$ These findings suggest that monitoring circulating adiponectin and homocysteine levels could provide useful clinical information on the risk of developing MetS and provide effective targets for intervention aimed at modifying lifestyle. However, further studies, including economic evaluations and prospective studies, should investigate whether these markers would prove useful and cost-effective in the early identification of MetS. In this study, we found considerable heritability of MetS among AA. This provides direct support for performing genome-wide association studies in this population. Our finding also supports the hypothesis of lipid metabolism playing the central role in the development of MetS and strongly encourages additional efforts to identify the underlying susceptibility genes for this syndrome in AA.

Our results should be interpreted within the context of few limitations. We acknowledge that given our crosssectional observational design, our study can only confirm the associations of the factors with MetS but cannot prove the causality. We also recognise the considerable disagreement over the definition and diagnostic criteria related to MetS. Of the various available definitions, we used the ATPIII criteria as this is the most widely used definition in the USA. ${ }^{1}{ }^{24}$ It can be argued, however, that some other available definition of MetS could be equally valid and produce a somewhat different result. Though we have accounted for important individual covariates, our heritability estimates were influenced by shared environmental factors like childhood environment and neighbourhood factors, and thus our results could be slightly overestimated. One of the major strengths of our study is that our data, although crosssectional, come from a large community-based AA population, which is vastly understudied but has high prevalence of metabolic diseases including obesity, diabetes, hypertension and others. We are not aware of any published data that reported the associated factors and quantified the heritability of MetS among AA from such a big setting. Further, assessment of sociodemographic variables in the JHS was performed uniformly and precise techniques were used to measure all physiological and biochemical values, which makes our findings reliable. JHS also has a complex and extended pedigree structure with a large sample, which provided us a more robust statistical ground to detect genetic effects than nuclear families, twin pair data or sib-pair data.

We report the associations of important factors and significant heritability estimates of MetS and its components among JHS AA families. Our data suggest the inclusion of biomarkers like adiponectin and homocysteine to improve early identification of MetS. We have demonstrated significant heritability estimates for the MetS itself, and also for its individual components. The results strongly encourage efforts to identify the underlying susceptibility genes for this syndrome in AA. Further exploration of the genetic and environmental factors of MetS among AAs will lead to a more comprehensive understanding and better therapeutic options for the syndrome, and ultimately lead to improved cardiovascular health.

Acknowledgements The authors would like to thank the Jackson Heart Study participants and the staff for their important contributions to the study of determinants of health in African Americans.

Contributors SKD and RJK conceptualised the study. RJK and RX completed the main data analysis. RJK and SKD prepared the manuscript. SYG, PR and MS contributed to the study design, interpretation of data and the preparation of the manuscript. All authors read and approved the final manuscript.

Funding This research was supported by the Intramural Research Program of the National Institutes of Health. The Jackson Heart Study is supported by contracts HHSN2682013000 46C, HHSN2682013000 47C, HHSN268201300048C, HHSN268201300049C, HHSN268201300050C from the National Heart, Lung, and Blood Institute and the National Institute on Minority Health and Health Disparities.

Competing interests None declared.

Ethics approval University of Mississippi Medical Center Institutional Review Board and National Human Genome Research Institute Institutional Review Board.

Provenance and peer review Not commissioned; externally peer reviewed.

Data sharing statement No additional data are available.

Open Access This is an Open Access article distributed in accordance with the Creative Commons Attribution Non Commercial (CC BY-NC 4.0) license, which permits others to distribute, remix, adapt, build upon this work noncommercially, and license their derivative works on different terms, provided the original work is properly cited and the use is non-commercial. See: http:// creativecommons.org/licenses/by-nc/4.0/ 


\section{REFERENCES}

1. Ford ES, Li C, Zhao G. Prevalence and correlates of metabolic syndrome based on a harmonious definition among adults in the US. J Diabetes 2010;2:180-93.

2. Bhargava A. A longitudinal analysis of the risk factors for diabetes and coronary heart disease in the Framingham Offspring Study. Popul Health Metr 2003;1:3.

3. Carnethon MR, Loria CM, Hill JO, et al. Risk factors for the metabolic syndrome: the Coronary Artery Risk Development in Young Adults (CARDIA) study, 1985-2001. Diabetes Care 2004;27:2707-15.

4. Sabo RT, Lu Z, Deng X, et al. Parental and offspring associations of the metabolic syndrome in the Fels Longitudinal Study. Am J Clin Nutr 2012;96:461-6.

5. Feng $\mathrm{Y}$, Zang $\mathrm{T}$, Xu X. Familial aggregation of metabolic syndrome and its components in a large Chinese population. Obesity (Silver Spring) 2008;16:125-9.

6. Santos DM, Katzmarzyk PT, Tregouet DA, et al. Familial aggregation of metabolic syndrome indicators in portuguese families. Biomed Res Int 2013;2013:314823.

7. Bosy-Westphal A, Onur S, Geisler C, et al. Common familial influences on clustering of metabolic syndrome traits with central obesity and insulin resistance: the Kiel obesity prevention study. Int J Obes 2007;31:784-90.

8. Groop L, Forsblom C, Lehtovirta M, et al. Metabolic consequences of a family history of NIDDM (the Botnia study): evidence for sex-specific parental effects. Diabetes 1996;45:1585-93.

9. Freeman MS, Mansfield MW, Barrett $\mathrm{JH}$, et al. Heritability of features of the insulin resistance syndrome in a community-based study of healthy families. Diabet Med 2002;19:994-9.

10. Bellia A, Giardina E, Lauro D, et al. "The Linosa Study": epidemiological and heritability data of the metabolic syndrome in a Caucasian genetic isolate. Nutr Metab Cardiovasc Dis 2009;19:455-61.

11. Henneman $P$, Aulchenko YS, Frants RR, et al. Prevalence and heritability of the metabolic syndrome and its individual components in a Dutch isolate: the Erasmus Rucphen Family study. J Med Genet 2008;45:572-7.

12. Lin HF, Boden-Albala B, Juo SH, et al. Heritabilities of the metabolic syndrome and its components in the Northern Manhattan Family Study. Diabetologia 2005;48:2006-12.

13. Bayoumi RA, Al-Yahyaee SA, Albarwani SA, et al. Heritability of determinants of the metabolic syndrome among healthy Arabs of the Oman family study. Obesity (Silver Spring) 2007;15: $551-6$

14. Vattikuti S, Guo J, Chow CC. Heritability and genetic correlations explained by common SNPs for metabolic syndrome traits. PLoS Genet 2012;8:e1002637.

15. Luke A, Guo X, Adeyemo AA, et al. Heritability of obesity-related traits among Nigerians, Jamaicans and US black people. Int J Obes Relat Metab Disord 2001;25:1034-41.

16. Iliadou A, Snieder $\mathrm{H}$, Wang $\mathrm{X}$, et al. Heritabilities of lipids in young European American and African American twins. Twin Res Hum Genet 2005;8:492-8.

17. Price RA, Reed DR, Guido NJ. Resemblance for body mass index in families of obese African American and European American women. Obes Res 2000;8:360-6.

18. Go AS, Mozaffarian D, Roger VL, et al. Heart disease and stroke statistics--2013 update: a report from the American Hear Association. Circulation 2013;127:e6-e245.

19. van Dongen J, Willemsen G, Chen WM, et al. Heritability of metabolic syndrome traits in a large population-based sample. J Lipid Res 2013;54:2914-23.

20. Taylor HA Jr, Wilson JG, Jones DW, et al. Toward resolution of cardiovascular health disparities in African Americans: design and methods of the Jackson Heart Study. Ethn Dis. 2005;15(4 Suppl 6):4-17

21. Wilson JG, Rotimi CN, Ekunwe L, et al. Study design for genetic analysis in the Jackson Heart Study. Ethn Dis 2005;15(4 Suppl 6):30-7.

22. Taylor HA Jr. The Jackson Heart Study: an overview. Ethn Dis 2005;15(4 Suppl 6):1-3.

23. Carpenter MA, Crow R, Steffes M, et al. Laboratory, reading center and coordinating center data management methods in the Jackson Heart Study. Am J Med Sci 2004;328:131-44.

24. Expert Panel on Detection, Evaluation, and Treatment of High Blood Cholesterol in Adults. Executive Summary of The Third Report of The National Cholesterol Education Program (NCEP) Expert Panel on Detection, Evaluation, And Treatment of High Blood Cholesterol In Adults (Adult Treatment Panel III). JAMA 2001;285:2486-97.
25. Grundy SM, Brewer HB Jr, Cleeman JI, et al. Definition of metabolic syndrome: report of the National Heart, Lung, and Blood Institute/ American Heart Association conference on scientific issues related to definition. Arterioscler Thromb Vasc Biol 2004;24:e13-18.

26. Cohen S, Kamarck T, Mermelstein R. A global measure of perceived stress. J Health Soc Behav 1983;24:385-96.

27. Dubbert PM, Carithers T, Ainsworth BE, et al. Physical activity assessment methods in the Jackson Heart Study. Ethn Dis 2005;15 (4 Suppl 6):56-61.

28. SAS® 9.3, Copyright (C) 2011. In SAS Institute Inc. Cary, NC, USA.

29. Szabo de Edelenyi F, Goumidi L, Bertrais S, et al. Prediction of the metabolic syndrome status based on dietary and genetic parameters, using Random Forest. Genes Nutr 2008;3:173-6.

30. Duggirala R, Williams JT, Williams-Blangero $S$, et al. A variance component approach to dichotomous trait linkage analysis using a threshold model. Genet Epidemiol 1997;14:987-92.

31. Metelskaya VA, Shkolnikova MA, Shalnova SA, et al. Prevalence, components, and correlates of metabolic syndrome (MetS) among elderly Muscovites. Arch Gerontol Geriatr 2012;55:231-7.

32. Mokan M, Galajda P, Pridavkova D, et al. Prevalence of diabetes mellitus and metabolic syndrome in Slovakia. Diabetes Res Clin Pract 2008;81:238-42.

33. Cankurtaran M, Halil M, Yavuz BB, et al. Prevalence and correlates of metabolic syndrome (MS) in older adults. Arch Gerontol Geriatr 2006;42:35-45.

34. Luepker RV, Rosamond WD, Murphy R, et al. Socioeconomic status and coronary heart disease risk factor trends. The Minnesota Heart Survey. Circulation 1993;88(5 Pt 1):2172-9.

35. Mackenbach JP, Stirbu I, Roskam AJ, et al. Socioeconomic inequalities in health in 22 European countries. $N$ Engl J Med 2008;358:2468-81.

36. Brunner EJ, Marmot MG, Nanchahal K, et al. Social inequality in coronary risk: central obesity and the metabolic syndrome. Evidence from the Whitehall II study. Diabetologia 1997;40:1341-9.

37. Berlin I, Lin S, Lima JA, et al. Smoking Status and Metabolic Syndrome in the Multi-Ethnic Study of Atherosclerosis. A cross-sectional study. Tob Induc Dis 2012;10:9.

38. Sun K, Liu J, Ning G. Active smoking and risk of metabolic syndrome: a meta-analysis of prospective studies. PLOS ONE 2012;7:17

39. Akbartabartoori M, Lean ME, Hankey CR. Relationships between cigarette smoking, body size and body shape. Int J Obes (Lond) 2004;29:236-43.

40. Filozof C, Fernandez Pinilla MC, Fernandez-Cruz A. Smoking cessation and weight gain. Obes Rev 2004;5:95-103.

41. Poulsen P, Vaag A, Kyvik K, et al. Genetic versus environmental aetiology of the metabolic syndrome among male and female twins. Diabetologia 2001;44:537-43.

42. Monda KL, North KE, Hunt SC, et al. The genetics of obesity and the metabolic syndrome. Endocr Metab Immune Disord Drug Targets 2010;10:86-108.

43. Kristiansson K, Perola M, Tikkanen E, et al. Genome-Wide Screen for Metabolic Syndrome Susceptibility Loci Reveals Strong Lipid Gene Contribution But No Evidence for Common Genetic Basis for Clustering of Metabolic Syndrome Traits. Cir Cardiovas Genet 2012;5:242-9.

44. Joy T, Lahiry P, Pollex RL, et al. Genetics of metabolic syndrome. Curr Diab Rep 2008;8:141-8.

45. Povel CM, Boer JM, Reiling E, et al. Genetic variants and the metabolic syndrome: a systematic review. Obes Rev 2011;12:952-67.

46. Lyssenko V, Sjögren M, Almgren P, et al. Genetic prediction of the metabolic syndrome. Diabetes Metab Syndr 2008;2:245-52.

47. Kim JY, Ahn SV, Yoon JH, et al. Prospective study of serum adiponectin and incident metabolic syndrome: the ARIRANG study Diabetes Care 2013;36:1547-53.

48. Juonala M, Saarikoski LA, Viikari JS, et al. A longitudinal analysis on associations of adiponectin levels with metabolic syndrome and carotid artery intima-media thickness. The Cardiovascular Risk in Young Finns Study. Atherosclerosis 2011;217:234-9.

49. Barazzoni R, Silva V, Singer P. Clinical biomarkers in metabolic syndrome. Nutr Clin Pract 2014;29:215-21.

50. Hajer GR, van der Graaf Y, Olijhoek JK, et al. Levels of homocysteine are increased in metabolic syndrome patients but are not associated with an increased cardiovascular risk, in contrast to patients without the metabolic syndrome. Heart 2007;93:216-20.

51. Esteghamati A, Hafezi-Nejad N, Zandieh A, et al. Homocysteine and metabolic syndrome: From clustering to additional utility in prediction of coronary heart disease. J Cardiol 2014;64: 290-6. 